\title{
Growing Black Chokeberry (Aronia melanocarpa) in Cut-over Peatlands
}

\author{
Julie Bussières, Stéphanie Boudreau, Guillaume Clément-Mathieu, \\ Blanche Dansereau, and Line Rochefort ${ }^{1}$ \\ Département de Phytologie, Université Laval, Québec, QC, G1V 0A6, \\ Canada
}

Additional index words. bog, peat, rehabilitation, reclamation, small fruit, northern berries

\begin{abstract}
This project was established to evaluate the feasibility of black chokeberry [Aronia melanocarpa (Michx.) Ell.] culture on Canadian cut-over peatlands and to define its appropriate production practices. We tested the effects of different fertilizer rates, application methods, and mulches on the vegetative development and berry production of seedlings over a 6-year period (2000 to 2006). Fertilization was essential for survival of the plants. A low fertilizer rate $(131 \mathrm{~g} /$ plant of $1.7 \mathrm{~N}-4.1 \mathrm{P}-12 \mathrm{~K})$ ensured adequate vegetative development for good establishment. Applying such a rate for 2 consecutive years proved to be more beneficial than a single dose of fertilizer for increasing plant height, crown width, and height growth. However, fruit yield was best when fertilized with the highest dose tested $(550 \mathrm{~g} /$ plant of $3.4 \mathrm{~N}-8.3 \mathrm{P}-24.2 \mathrm{~K})$. Black plastic mulch had a positive effect on height, width, and growth of the plants. More weeds were observed when the fertilizer was applied to the surface as compared with soil incorporation. However, this study revealed that black chokeberry is tolerant of weeds. Based on these results, black chokeberry is a promising plant for the management of cut-over peatlands for both vegetative growth and fruit production.
\end{abstract}

In Eastern Canada, peatlands are mined for the horticultural properties of peat. When peat mining ends, the natural revegetation of the site is usually slow and scarce (Poulin et al., 2005). Generally, ecological restoration of cut-over peatlands follows peat harvesting with respect to the "no net loss" policy for the management of wetlands in North America (Lynch-Stewart, 1992). Planting small fruit plants on cut-over peatlands could be considered a complement to ecological restoration (Rochefort et al., 2003) or as a reclamation option. Berry plantations in restoration projects could increase landscape heterogeneity and facilitate the return of typical peatland bird species. As a reclamation option, added value could be gained from formerly abandoned sites.

\footnotetext{
Received for publication 23 Oct. 2007. Accepted for publication 10 Dec. 2007.

This study was supported by the Natural Sciences and Engineering Research Council of Canada (NSERC) and by industrial partners of the Industrial Research Chair in Peatland Management led by Line Rochefort.

We thank Fafard \& Frères ltée, especially Juana Elustondo, for their implication and support in this project. We also thank research assistants who participated in field work: Annie Jacob, Sharon Boisvert, Luc Miousse, Rosalie Cliche, Patrick Faubert, Ariane Massé, Jacinthe Letendre, and Véronique Bouchard. Finally, we are grateful to anonymous reviewers for useful comments and suggestions on earlier drafts of the manuscript.

${ }^{1}$ To whom reprint requests should be addressed; e-mail Line.Rochefort@fsaa.ulaval.ca
}

Among small fruits native to North America, black chokeberry (Aronia melanocarpa) is a promising candidate for use in cut-over peatlands. This species produces black edible fruits, readily eaten by birds, and is known for its low maintenance requirements; slight pruning is required and low occurrence of pests and diseases has been observed (Finn, 1999; McKay, 2001; Richer et al., 1997; Strik et al., 2003). Fruits also have antimutagenic properties resulting from their high anthocyanin content (Gasiorowski et al., 1997). Black chokeberry is already commercially grown, especially in Europe, where its fruits are used in several juices, alcoholic or energizing drinks, and in food colorant.

Very little research on small fruit culture on cut-over peatlands has been done because large-scale industrial peat harvesting is relatively recent. The first small fruit plantings on industrial cut-over sites were done in Europe in the mid-1970s (Paal, 1992). Most plantings are found in Estonia, where blueberry ( $\mathrm{Vac}$ cinium angustifolium Ait.) and cranberry ( $V$. oxycoccos L.) are also successfully grown on cut-over peatlands (Noormets, 2006; Noormets et al., 2004; Paal, 1992; Paal and Paal, 2002). A few small fruit trials have been done on Canadian cut-over peatlands, but data are rudimentary and not easily available. Cut-over peatlands are interesting grounds for berry production because they are pathogen-free and initially weed-free (Virkajärvi and Huhta, 1996). Because cut-over peatlands have never received fertilizers or pesticides, there is a potential for establishing organic production of fruits, vegetables, or medicinal plants (Kukkonen et al., 1999;
Vestberg et al., 1999). However, small fruit production on cut-over peatlands can be challenging. Intensive drainage required during peat harvesting results in a deep and unstable water table level that represents a risk of water deficit for subsequent plantings. The water table level may periodically remain high as a result of the low hydraulic conductivity of peat with associated risk of anoxia in the root zone. Moreover, the remaining peat has a low thermal conductivity, is highly acidic, and has a low nutritional content (Myllis, 1996; Wind-Mulder et al., 1996). Hence, fertilization is required for plant growth and productive fruit yield in cut-over peatlands (Noormets et al., 2004; Paal and Paal, 2002).

The objectives of this project were to evaluate the feasibility of black chokeberry (Aronia melanocarpa) culture on Canadian cut-over peatlands and to define its appropriate production practices.

\section{Materials and Methods}

Two experiments were established at St-Bonaventure cut-over peatlands (lat. $45^{\circ} 57^{\prime} \mathrm{N}$, long. $\left.72^{\circ} 42^{\prime} \mathrm{W}\right)$ southwest of Quebec, Canada. This bog peatland was originally drained for peat harvesting using the Haku-Peco technique (Andriesse, 1988) and operations ended in 1999. Fields were then flattened and additional drains were dug to improve drainage. Peat depth varied from 47 to $115 \mathrm{~cm}$ (average, $78 \mathrm{~cm}$; median, $81 \mathrm{~cm}$ ) and peat fields were 11 to $41 \mathrm{~m}$ wide and $250 \mathrm{~m}$ long on average. Nutrient content was lower than the average peat chemistry for natural or cut-over peatlands (WindMulder et al., 1996): $195.5 \mathrm{mg} \cdot \mathrm{kg}^{-1}$ of $\mathrm{N}-\mathrm{NH}_{4}, 8.3 \mathrm{mg} \cdot \mathrm{kg}^{-1}$ of $\mathrm{N}-\mathrm{NO}_{3}, 12.9 \mathrm{~g} \cdot \mathrm{kg}^{-1}$ of total nitrogen, $28 \mathrm{mg} \cdot \mathrm{kg}^{-1}$ of phosphorus, $121 \mathrm{mg} \cdot \mathrm{kg}^{-1}$ of potassium, and $9 \mathrm{mg} \cdot \mathrm{kg}^{-1}$ of copper. Electric conductivity was higher (338 $\mu \mathrm{S} \cdot \mathrm{cm}^{-1}$ ) and $\mathrm{pH}$ (3.7) was similar to that reported for cut-over peatlands.

The nearest meteorological station (Drummondville: $45^{\circ} 52^{\prime} \mathrm{N}, 7^{\circ} 28^{\prime} \mathrm{W}$ ) reported annual average precipitation of $1125 \mathrm{~mm}$, of which $349 \mathrm{~mm}$ falls as snow, as well as mean temperatures of $-10.7^{\circ} \mathrm{C}$ in January and $20.8^{\circ} \mathrm{C}$ in July with an annual average of $5.9{ }^{\circ} \mathrm{C}$ (Environment Canada, 2006a; equivalent of USDA Hardiness Zone $4 b)$. Total rainfall for the growing season (May to September) was $606 \mathrm{~mm}$ in 2000 , $389 \mathrm{~mm}$ in $2001,431 \mathrm{~mm}$ in $2002,483 \mathrm{~mm}$ in 2003, $492 \mathrm{~mm}$ in 2004, and $482 \mathrm{~mm}$ in 2005 (Environment Canada, 2006b). Water table depth measured in one well throughout the summer of 2002 remained below $50 \mathrm{~cm}$ from July to September.

Expt. 1: Fertilizer rates. Seedlings (tray of 45 plants or $110 \mathrm{~cm}^{3}$, height unrecorded; Phytoclone and Québec Multiplants nursery) were planted between 8 May 2000 and 16 June 2000. Date of planting was not recorded precisely because the black chokeberry plantation was part of a larger reclamation project realized by the peat company and involving other species. Planting was done successively 
on each experimental block and seedlings were randomly assigned to each treatment. Plants were planted at $1.5 \mathrm{~m}$ spacing within rows with $3 \mathrm{~m}$ between rows for a density of 2222 plants/ha.

Four fertilizer rates were tested to determine the optimal rate for establishment and vegetative development of a black chokeberry planting on cut-over peat fields. These rates were chosen based on recommendations for field-grown broadleaf shrubs (Hamel, 1986). Based on the chemical analysis of the residual peat substrate, $275 \mathrm{~g} /$ plant $\left(610 \mathrm{~kg} \cdot \mathrm{ha}^{-1}\right)$ of added fertilizer $(3.4 \mathrm{~N}-$ $8.3 \mathrm{P}-24.2 \mathrm{~K}$ composed of a granular mix of ammonium nitrate, super phosphate, and potassium chloride) was estimated to be sufficient for plant nutrition. Because this was the first attempt to grow these plants on this poor growing substrate, treatments were designed to confirm the calculated required rate: 1) an unfertilized control, 2) $137.5 \mathrm{~g} /$ plant, 3) $275 \mathrm{~g} /$ plant, and 4) $550 \mathrm{~g} /$ plant, i.e., half, full, and twice the recommended rate (Hamel, 1986). Fertilizer was surface-applied within $10 \mathrm{~cm}$ around plants in mid-June 2000 . Weeds were mowed between and within rows two to three times each year with a land mower.

Plant numbers in the experimental units varied from 76 to 294 as a result of the variability in field width. The fertilizer rates were tested within a randomized complete block design with six repetitions grouped as blocks.

Plant survival and plant height were first surveyed in Oct. 2000 and then in Sept. 2002, 2004, and 2005 after one, three, five, and six growing seasons. Measurements were taken and averaged on sampling units of 16 plants (2000, 2004, and 2005) or nine plants (2002) for each experimental unit, except for survival data in 2002, which was measured on all plants. Survival (percent) was calculated as the number of living plants compared with the initial number of planted seedlings. Height (centimeters) was measured from the soil to the highest branches, respecting the growth form of each plant. Fruit yield (grams per plant) was measured in 2005, 6 years after planting, when two-thirds of fruits were visually ripe (average $65 \%$ and median $73 \%$ of ripe fruits per plant; 24 to 26 Aug. 2005). The total weight of fruits (grams) per plant was averaged for each experimental unit.

Expt. 2: Fertilizer regime and mulching. The second experiment was designed to compare the effect of a lower fertilizer rate than the one applied in Expt. 1, application methods of fertilizer, and mulching on black chokeberry survival and vegetative development. The fertilizer formulation for this experiment was $1.7 \mathrm{~N}-4.1 \mathrm{P}-12 \mathrm{~K}$, a granular mix of urea, phosphate rock, and potassium chloride, in which $262.4 \mathrm{~g} / \mathrm{plant}$ corresponded to the $137.5 \mathrm{~g} /$ plant rate of the formulation used in the previous experiment. The forms of nitrogen and phosphorus for Expt. 2 were chosen because they were organic-based fertilizers and less soluble than the forms in the previous experiment.
Seedlings $\left[110 \mathrm{~cm}^{3}\right.$, mean height $( \pm \mathrm{SD})$ of $44.8 \mathrm{~cm}( \pm 4.5)$; Aiglon nursery] were planted on 17 and 18 May 2004 at the same density as in the previous experiment and randomly assigned to blocks and treatments. Seven treatments were applied: 1) control without fertilizer or plastic mulch (C);2) $131.2 \mathrm{~g} / \mathrm{plant}$ applied to the surface without mulch (1/2Fs); 3) two applications of $131.2 \mathrm{~g} /$ plant applied to the surface in both Spring 2004 and 2005 without mulch $(1 / 2 \mathrm{Fs} \times 2)$; 4) $262.4 \mathrm{~g} /$ plant applied to the surface without mulch (Fs); 5) $262.4 \mathrm{~g} /$ plant applied to the surface with mulch (FsM); 6) $262.4 \mathrm{~g} /$ plant incorporated into the soil without mulch (Fi); and 7) $262.4 \mathrm{~g} /$ plant incorporated into soil with mulch (FiM). Fertilizer was either surface-applied within $10 \mathrm{~cm}$ of plants or incorporated into three holes of $5 \mathrm{~cm}$ depth, $10 \mathrm{~cm}$ from each plant depending on treatment. Fertilizer was applied on 19 May 2004 and followed by manual installation of plastic mulch (black polyethylene film, $1.2 \mathrm{~m}$ wide and $0.058 \mathrm{~mm}$ thick). Plants in treatment 1/2Fs $\times 2$ were refertilized on 9 May 2005.

Each experimental unit consisted of a row of eight plants and the treatments were tested using a randomized complete block design replicated four times on the $30 \mathrm{~m}$ wide and $210 \mathrm{~m}$ long cut-over peat field of St-Bonaventure peatland.

Total survival (percent), height (centimeters), and crown width (centimeters) of the plants were measured on 26 Aug. 2005. The height had also been measured previously on 11 Aug. 2004 to calculate the growth in height (centimeters) of each plant for a 1year period (Aug. 2004 to Aug. 2005; annual growth was fixed to 0 when negative). Measurements were done on the six central plants of a row to avoid edge effects. Height (centimeters) was measured as in the first experiment. Width (centimeters) was calculated from the average of two crown width measurements on each plant. Measurements were taken above plant canopy parallel and perpendicular to the row. Weed coverage (percent) was rated visually on a scale of 1 to 5 for each experimental unit: 1 for $0 \%$ to $20 \%$ groundcover occupied by weeds, 2 for $21 \%$ to $40 \%, 3$ for $41 \%$ to $60 \%, 4$ for $61 \%$ to $80 \%$, and 5 for $81 \%$ to $100 \%$. The middle value of each class was used in statistical analysis and results.

Statistical analyses. Analyses of variance were used to test the effect of treatments on each dependent variable. For Expt. 1 (fertilizer rates), three a priori polynomial contrasts were further used to test for trends with fertilizer rates (Table 1) whereas for Expt. 2 (fertilizer regime and mulching), six a priori contrasts were chosen according to our hypotheses (Table 2). Analyses were done using the GLM procedure of the SAS Statistical System software (version 8; SAS Institute, Cary, NC) with a significance level of $P<0.05$. Normality and homogeneity of variance were tested and the following transformations were applied for Expt. 1 only: arcsinus [square root $(x)$ ] on 2002 survival and $\log _{10}(x+1)$ on 2005 fruit yield (Table 1)

\section{Results}

Expt. 1: Fertilizer rates. After one growing season, black chokeberry plants showed a high survival rate in all treatments; in fact, $95 \%$ ( $\pm 2 \mathrm{SE}$ ) of all plants survived (Fig. 1). Three years after establishment, the survival

Table 1. Analyses of variance and polynomial a priori contrasts testing four fertilizer rates $(0,137.5,275$, and $550 \mathrm{~g} /$ plant of $3.4 \mathrm{~N}-8.3 \mathrm{P}-24.2 \mathrm{~K})$ on survival $(\%)$ and height $(\mathrm{cm})$ of black chokeberry measured after one, three, five, and six growing seasons and fruit yield (g/plant) measured after six growing season at St-Bonaventure (Quebec) cut-over peatland.

\begin{tabular}{|c|c|c|c|c|c|c|c|c|c|}
\hline & \multirow[b]{2}{*}{$d f$} & \multicolumn{2}{|c|}{ Year 1} & \multicolumn{2}{|c|}{ Year 3} & \multicolumn{2}{|c|}{ Year 5} & \multicolumn{2}{|c|}{ Year 6} \\
\hline & & $F$ & $P$ & $F$ & $P$ & $F$ & $P$ & $F$ & $P$ \\
\hline \multicolumn{10}{|l|}{ Survival $^{z}$} \\
\hline Block & 5 & 1.2 & & 1.2 & & 0.3 & & 0.2 & \\
\hline Rate & 3 & 1.2 & 0.34 & 4.2 & 0.03 & 1.9 & 0.17 & 13.1 & $<0.001$ \\
\hline Linear & 1 & 3.6 & 0.08 & 11.2 & 0.004 & 0.6 & 0.47 & 4.4 & 0.05 \\
\hline Quadratic & 1 & 0.01 & 0.93 & 0.9 & 0.35 & 4.0 & 0.06 & 28.3 & $<0.001$ \\
\hline Cubic & 1 & 0.01 & 0.92 & 0.28 & 0.61 & 1.2 & 0.30 & 6.6 & 0.02 \\
\hline Error & 15 & & & & & & & & \\
\hline Total & 23 & & & & & & & & \\
\hline \multicolumn{10}{|l|}{ Height } \\
\hline Block & 5 & 14.5 & & 3.6 & & 1.1 & & 4.5 & \\
\hline Rate & 3 & 4.9 & 0.01 & 25.1 & $<0.001$ & 4.4 & 0.02 & 32.3 & $<0.001$ \\
\hline Linear & 1 & 8.4 & 0.01 & 28.8 & $<0.001$ & 7.6 & 0.01 & 57.2 & $<0.001$ \\
\hline Quadratic & 1 & 3.4 & 0.09 & 39.0 & $<0.001$ & 5.42 & 0.03 & 37.9 & $<0.001$ \\
\hline Cubic & 1 & 2.9 & 0.11 & 7.6 & 0.01 & 0.3 & 0.58 & 2.0 & 0.18 \\
\hline Error & 15 & & & & & & & & \\
\hline Total & 23 & & & & & & & & \\
\hline \multicolumn{10}{|l|}{ Fruit yield ${ }^{y}$} \\
\hline Block & 5 & - & & - & & - & & 12.9 & \\
\hline Rate & 3 & - & & - & & - & & 7.7 & 0.002 \\
\hline Linear & 1 & - & & - & & - & & 22.4 & $<0.001$ \\
\hline Quadratic & 1 & - & & - & & - & & 0.4 & 0.55 \\
\hline Cubic & 1 & - & & - & & - & & 0.2 & 0.65 \\
\hline Error & 15 & & & & & & & & \\
\hline Total & 23 & & & & & & & & \\
\hline
\end{tabular}

${ }^{\mathrm{z}}$ Arcsinus transformation $\{\operatorname{arcsinus~[square~root~}(x)]$ \} applied to survival year 3 .

${ }^{\mathrm{y}} \log$ transformation $\left[\log _{10}(x+1)\right]$ applied to fruit yield year 6 . 
Table 2. Analyses of variance and simple a priori contrasts testing the effects of fertilization regime (rate, split application, and application method) and mulching on survival $(\%)$, height $(\mathrm{cm})$, annual height growth gain in 1 year $(\mathrm{cm})$, and crown width $(\mathrm{cm})$ of black chokeberry, as well as weed coverage $(\%)$ measured after two growing seasons in St-Bonaventure (Quebec) cut-over peatland.

\begin{tabular}{|c|c|c|c|c|c|c|c|c|c|c|c|}
\hline & $d f$ & Survival $F$ & $P$ & Height $F$ & $P$ & Growth $F$ & $P$ & Width $F$ & $P$ & Weeds $F$ & $P$ \\
\hline$\overline{\text { Block }}$ & 3 & 0.3 & & 0.3 & & 0.6 & & 1.9 & & 1.8 & \\
\hline Treatment & 6 & 2.9 & 0.04 & 8.0 & $<0.001$ & 7.3 & $<0.001$ & 14.4 & $<0.001$ & 13.9 & $<0.001$ \\
\hline \multicolumn{12}{|l|}{ Contrasts $^{\mathrm{z}}$} \\
\hline Rate: Fs vs $1 / 2 \mathrm{Fs}$ & 1 & 0.7 & 0.42 & 0.1 & 0.82 & 0.3 & 0.61 & 0.4 & 0.55 & 14.7 & 0.001 \\
\hline \multicolumn{12}{|l|}{ Reapplication: } \\
\hline $1 / 2 \mathrm{Fs}$ vs $1 / 2 \mathrm{Fs} \times 2$ & 1 & 0.7 & 0.42 & 6.2 & 0.02 & 15.6 & $<0.001$ & 6.8 & 0.02 & 23.0 & $<0.001$ \\
\hline \multicolumn{12}{|l|}{ Split application: } \\
\hline Fs vs $1 / 2 \mathrm{Fs} \times 2$ & 1 & 0.0 & 1.00 & 7.4 & 0.01 & 11.8 & 0.003 & 10.3 & 0.005 & 0.9 & 0.35 \\
\hline \multicolumn{12}{|l|}{ Mulch: } \\
\hline Fs, Fi vs FsM, FiM & 1 & 8.4 & 0.01 & 4.6 & 0.05 & 8.0 & 0.01 & 21.9 & $<0.001$ & 19.4 & $<0.001$ \\
\hline \multicolumn{12}{|l|}{ Application method: } \\
\hline Fs vs Fi & 1 & 0.0 & 1.00 & 0.1 & 0.80 & 0.1 & 0.79 & 0.0 & 0.97 & 14.7 & 0.001 \\
\hline Control: C vs others & 1 & 1.2 & 0.30 & 35.0 & $<0.001$ & 19.1 & $<0.001$ & 55.4 & $<0.001$ & 15.0 & 0.001 \\
\hline Error & 18 & & & & & & & & & & \\
\hline Total & 27 & & & & & & & & & & \\
\hline
\end{tabular}

${ }^{\mathrm{z}}$ Treatments: $\mathrm{C}=$ control without fertilizer or mulch; $\mathrm{F}=262.4 \mathrm{~g} / \mathrm{plant}$ of $1.7 \mathrm{~N}-4.1 \mathrm{P}-12 \mathrm{~K} ; 1 / 2 \mathrm{~F}=131.2 \mathrm{~g} / \mathrm{plant} ; \times 2=$ annual application $($ repeated $2 \mathrm{years}) ; \mathrm{s}=$ fertilizer applied to the surface; $\mathrm{i}=$ incorporated into soil; $\mathrm{M}=$ with plastic mulch.
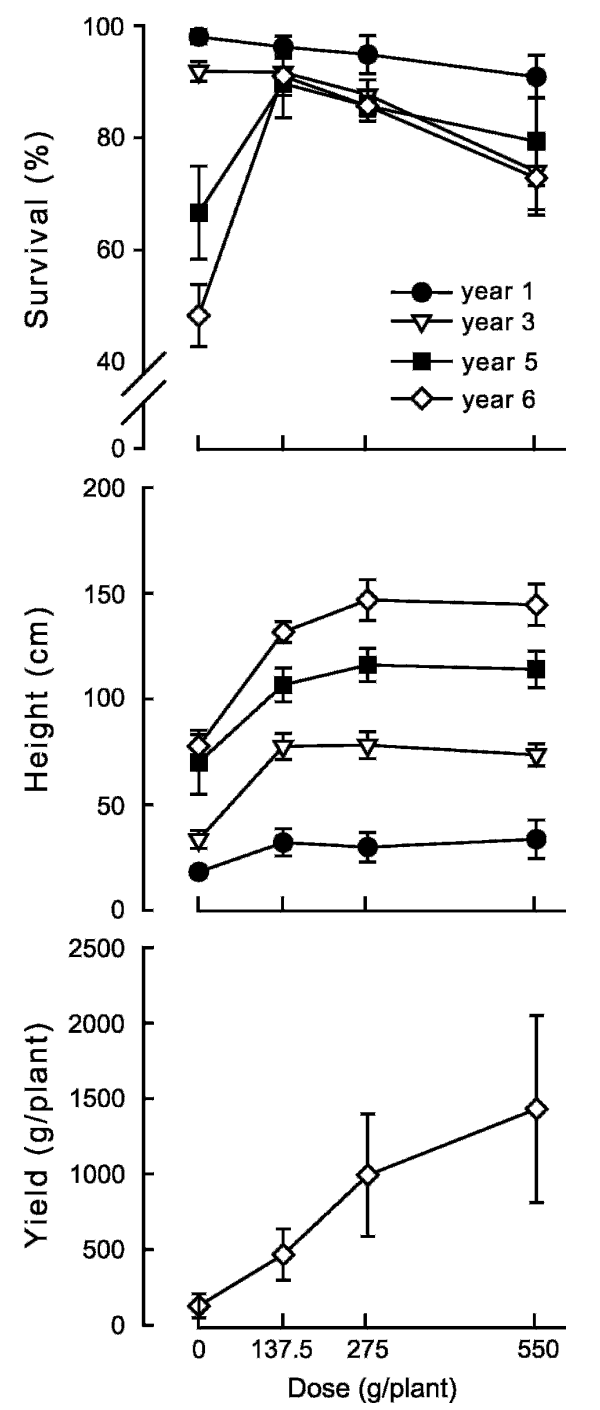

Fig. 1. Survival, height, and fruit yield (mean $\pm \mathrm{SE})$ of black chokeberry planted in St-Bonaventure (Quebec) cut-over peatland in response to four fertilizer rates of a surface-applied granular mix of ammonium nitrate, super phosphate, and potassium chloride $(3.4 \mathrm{~N}-8.3 \mathrm{P}-24.2 \mathrm{~K})$ measured after one, three, five, and six growing seasons.

Table 3. Survival, height, annual height growth, and crown width (mean $\pm \mathrm{sE}$ ) of black chokeberry planted in St-Bonaventure (Quebec) cut-over peatland in response to seven treatments testing fertilization (rate, split application, and application method of a $1.7 \mathrm{~N}-4.1 \mathrm{P}-12 \mathrm{~K}$ fertilizer) and mulching. ${ }^{\mathrm{z}}$

\begin{tabular}{lcccc}
\hline Treatments $^{\mathrm{y}}$ & $\begin{array}{c}\text { Survival } \\
(\%)\end{array}$ & $\begin{array}{c}\text { Height } \\
(\mathrm{cm})\end{array}$ & $\begin{array}{c}\text { Growth } \\
(\mathrm{cm})\end{array}$ & $\begin{array}{c}\text { Width } \\
(\mathrm{cm})\end{array}$ \\
\hline $\mathrm{C}$ & $100 \pm 0$ & $38.0 \pm 5.3$ & $2.6 \pm 0.8$ & $17.8 \pm 0.7$ \\
$1 / 2 \mathrm{Fs}$ & $96 \pm 4$ & $64.2 \pm 2.7$ & $9.9 \pm 1.7$ & $51.7 \pm 7$ \\
$1 / 2 \mathrm{Fs} \times 2$ & $100 \pm 0$ & $81.3 \pm 6.7$ & $26.3 \pm 4.5$ & $70.8 \pm 8.1$ \\
$\mathrm{Fs}$ & $100 \pm 0$ & $62.7 \pm 6.0$ & $12.0 \pm 3.7$ & $47.1 \pm 6.9$ \\
$\mathrm{FsM}$ & $96 \pm 4$ & $70.9 \pm 4.7$ & $20.3 \pm 3.3$ & $66.3 \pm 6.7$ \\
$\mathrm{Fi}$ & $100 \pm 0$ & $60.9 \pm 2.2$ & $10.9 \pm 2.4$ & $46.8 \pm 2$ \\
FiM & $83 \pm 7$ & $73.5 \pm 2.4$ & $19.2 \pm 1.9$ & $76.6 \pm 1.9$ \\
\hline
\end{tabular}

${ }^{\mathrm{z}}$ Measurements were taken after two growing seasons.

yTreatments: $\mathrm{C}=$ control without fertilizer or mulch; $\mathrm{F}=262.4 \mathrm{~g} /$ plant of $1.7 \mathrm{~N}-4.1 \mathrm{P}-12 \mathrm{~K} ; 1 / 2 \mathrm{~F}=131.2$ $\mathrm{g} /$ plant $\times 2=$ annual application (repeated 2 years); $\mathrm{s}=$ fertilizer applied to the surface; $\mathrm{i}=$ incorporated into soil; $\mathrm{M}=$ with plastic mulch.

rate remained generally high, although declining with increasing fertilizer application rate, from $92 \%( \pm 2 \mathrm{SE})$ without fertilization to $74 \%( \pm 7 \mathrm{SE})$ with $550 \mathrm{~g} /$ plant (Table 1; Fig. 1). After six growing seasons, survival was lowest in the control treatments $(48 \% \pm 5 \mathrm{SE})$. However, like in previous years, survival rate declined with increasing fertilizer rate.

Fertilization stimulated vegetative development of black chokeberry as estimated by height (Table 1; Fig. 1). After one growing season, the plants without fertilization were $18.1 \mathrm{~cm}( \pm 2.4 \mathrm{SE})$ tall compared with $33.6 \mathrm{~cm}$ $( \pm 9.1 \mathrm{SE})$ for those receiving the highest fertilizer rate. After three growing seasons, unfertilized plants were only $33.4 \mathrm{~cm}( \pm 4.2$ $\mathrm{SE}$ ), half of those receiving fertilizer ( 73 to $78 \mathrm{~cm} \pm 6 \mathrm{SE}$ ). The same pattern was observed after 5 and 6 years; plants without fertilization were smaller than those receiving fertilizer. However, adding more than $137.5 \mathrm{~g} /$ plant of fertilizer was not significantly beneficial to plant height, as confirmed by the significant quadratic contrasts (Table 2).

The black chokeberry plants started to yield fruits within 2 years of planting (data not shown). After six growing seasons, fruit yield was clearly increased by fertilization; $127 \mathrm{~g} /$ plant $( \pm 79 \mathrm{SE})$ of fruit on unfertilized plants compared with $1431 \mathrm{~g} /$ plant $( \pm 620 \mathrm{SE})$ were measured at the highest fertilizer rate.

Expt. 2: Fertilizer regime and mulching. Survival rate was high after two growing seasons, although somewhat reduced for plants covered by mulch (Tables 2 and 3 ).

Fertilizer rate (single application) and application method, either to the surface or incorporated, had no effect on black chokeberry vegetative development by the end of the second growing season (Tables 2 and 3 ). However, a split application of the lower rate $(1 / 2 \mathrm{Fs} \times 2-$ total rate equivalent to the single high application rate) resulted in height, growth, and crown width greater than that with only one low $(1 / 2 \mathrm{Fs})$ and one high $(\mathrm{Fs})$ application rate (Table 2; Fig. 2). Black chokeberry plants reached $81 \mathrm{~cm}$ in height (annual growth of $26 \mathrm{~cm}$ ) with two low-rate fertilizer applications compared with $64 \mathrm{~cm}$ with one application at either low or high rate.

Despite its negative effect on survival rate, mulch increased black chokeberry vegetative development during Summer 2005 (Table 2; Fig. 3). Indeed, mulched plants were $17 \%$ taller and $52 \%$ larger than those in nonmulched treatments.

Mulch and fertilizer incorporation both provided good weed control (Table 2; Fig. 4). Mulch decreased weed coverage by an average of $18 \%$ compared with nonmulched 

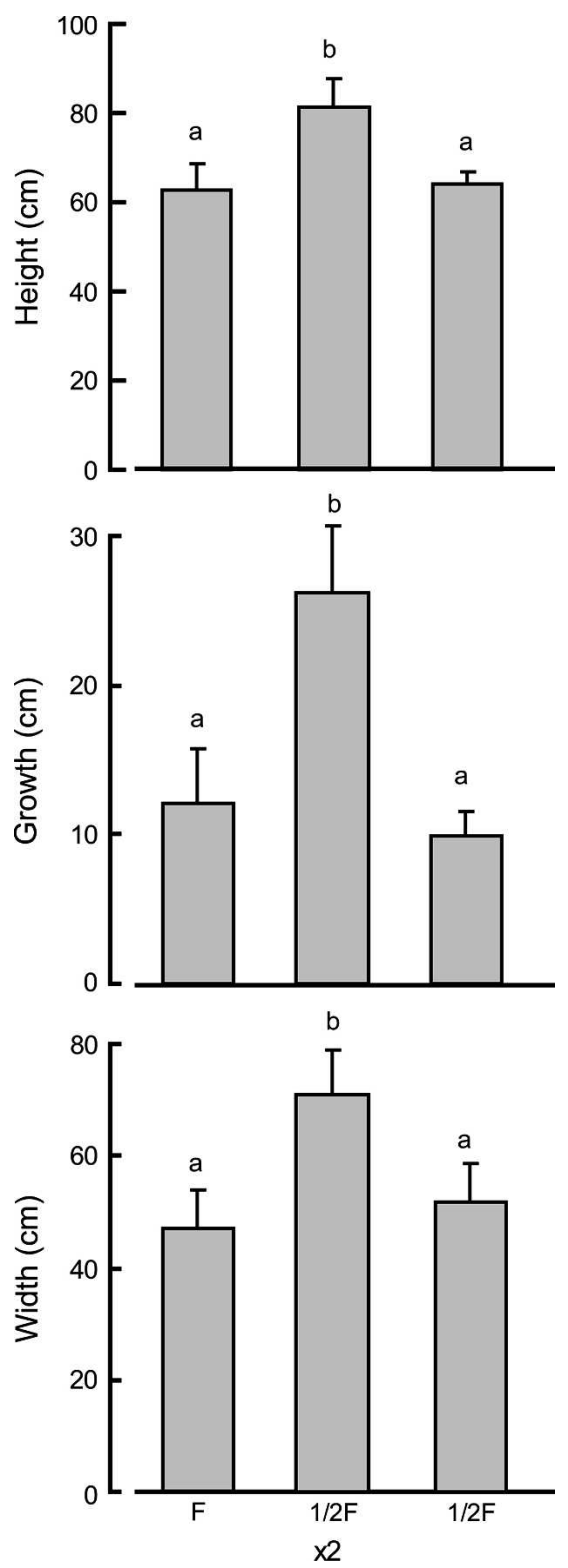

Fig. 2. Height, annual growth in height, and crown width (mean $\pm \mathrm{SE}$ ) of black chokeberry planted in St-Bonaventure (Quebec) cut-over peatland in response to three surface-applied fertilizer treatments. $\mathrm{F}=262.4 \mathrm{~g} / \mathrm{plant}$ of $1.7 \mathrm{~N}-4.1 \mathrm{P}$ $12 \mathrm{~K} ; 1 / 2 \mathrm{~F}=131.2 \mathrm{~g} /$ plant $; \times 2=$ split application (repeated over 2 years). Measurements were taken after two growing seasons.

treatments. In the nonmulched treatments, incorporation of the fertilizer limited weed invasion; surface application treatments (Fs) showed $70 \%$ weed coverage compared with $30 \%$ weed coverage for incorporation treatments (Fi). Additionally, high rates of fertilizer applied only once at planting (Fs) or split into two applications $(1 / 2 \mathrm{Fs} \times 2)$ were associated with greater weed invasion compared with that in areas receiving a low fertilizer rate applied once at planting $(1 / 2 \mathrm{Fs})$.

\section{Discussion}

The high survival rate of black chokeberry observed in both experiments indicates
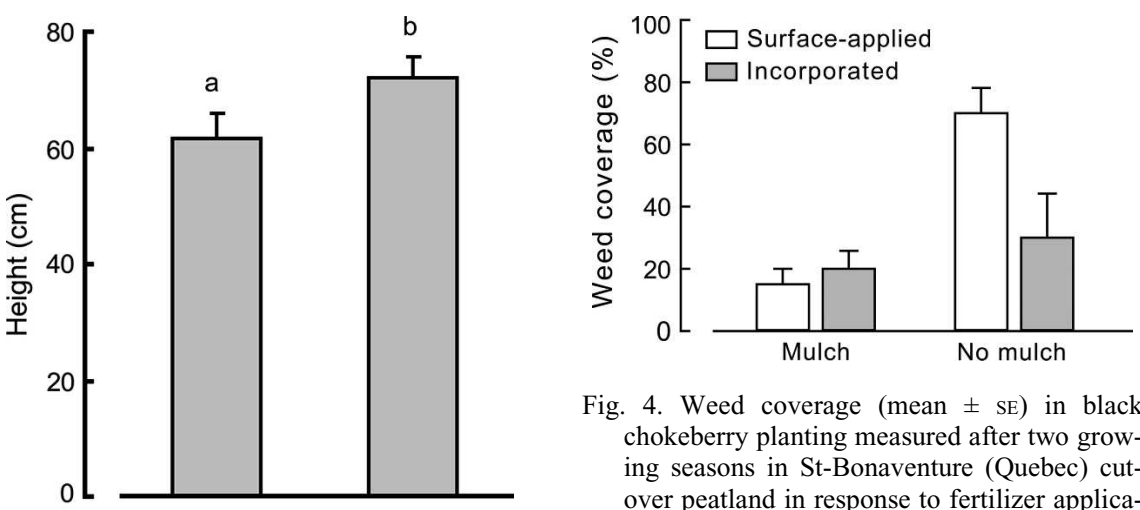

Fig. 4. Weed coverage (mean $\pm \mathrm{SE}$ ) in black chokeberry planting measured after two growing seasons in St-Bonaventure (Quebec) cutover peatland in response to fertilizer application method of $262.4 \mathrm{~g} /$ plant of fertilizer $(1.7 \mathrm{~N}-4.1 \mathrm{P}-12 \mathrm{~K})$ and mulching. Fertilizers were either surface-applied, within $10 \mathrm{~cm}$ around plants, or incorporated into the soil, in three holes $5 \mathrm{~cm}$ in depth, $10 \mathrm{~cm}$ from each plant. Mulching was applied as a black plastic (polyethylene film, $1.2 \mathrm{~m}$ wide and $0.058 \mathrm{~mm}$ thick). Measurements were taken after two growing seasons.

sublayer (Aro and Kaunisto, 2003). The cause of the increased mortality observed with increasing fertilizer rate in the first experiment is unclear but could be explained by mechanical injury from mowing. Plants could have been accidentally cut during weeding operations because they were hidden by weeds under higher fertilizer rates. In addition to nutrient deficiency, the high mortality of unfertilized plants may also be caused by their low visibility (as a result of their low height) during weeding operations.

The vegetative development of black chokeberry on cut-over peatlands was acceptable compared with results obtained in other studies on mineral soil. Survival rate was good, but plants grown at St-Bonaventure developed slowly (1-year delay) compared with those tested by the Quebec ornamental woody plant testing network (Richer et al., 1997), although development rate may have been influenced by seedling height at planting. At Balsgård (Sweden), Jeppsson (2000) obtained quite similar average plant height as measured in this study. The highest fertilizer rate tested in the Swedish experiment about matched our highest rate, although their plants were fertilized in subsequent growing seasons with decreasing rate applied each season. In Oregon, Strik et al. (2003) obtained greater growth with different black chokeberry cultivars ('Nero', 'Nowa', 'Wies', 'Albigowa', 'Kutno', 'Dabrowice', and 'Egerta') fertilized annually; 5-year-old plants in that study were up to $55 \%$ taller than the fertilized StBonaventure plants. The difference could be explained by the more favorable climatic conditions, which prevailed in Oregon but most probably by the use of higher-yield cultivars.

The desired outcome of black chokeberry planting should be taken into account when determining the fertilizer rate to be applied. In the first experiment, even the lowest of 
the four rates tested resulted in a substantial increase in the vegetative development of plants. In the second experiment, as low as $131.2 \mathrm{~g} /$ plant of $1.7 \mathrm{~N}-4.1 \mathrm{P}-12 \mathrm{~K}$ sufficed to ensure adequate growth. Therefore, a low rate is sufficient to produce plants in sizes fit for ecological restoration or other peatland rehabilitation projects where black chokeberry could be used.

However, as demonstrated in the first experiment, higher fertilizer rates are required for commercial fruit production of black chokeberry. The $1.4 \mathrm{~kg} /$ plant (3.1 $\mathrm{t} \cdot \mathrm{ha}^{-1}$ ) fruit yield at St-Bonaventure in 2005 at the highest fertilizer rate is still lower than yields obtained in optimal cultural condition plantings. For example, in the Quebec region (Québec, Canada), Rousseau and Bergeron (2003) harvested $2.4 \mathrm{~kg} /$ plant in trials carried out on private farms. In Sweden, Jeppsson (2000) harvested an average of $1.9 \mathrm{~kg} /$ plant for 3- to 5-year-old plantings (cv. Viking). Kask (1987) reported yields up to $6 \mathrm{~kg} / \mathrm{plant}$ in the best farms of the Soviet Union, where 17,800 ha of black chokeberry were commercially grown in the 1980s. However, all of these reported yields were low compared with the 13 to $24 \mathrm{~kg} /$ plant obtained for 5 year-old plantings of various selected cultivars of black chokeberry grown in Oregon (Strik et al., 2003). The higher yield in that study can be attributed to better climatic conditions or high-yielding cultivars. In addition, as far as we know, the Oregon plantings were the only ones reported to be netted against birds.

An annual fertilizer application should be considered, because, like the second experiment showed, a split application of two small annual doses produced stronger vegetative development of black chokeberry compared with the same amount in a single application. An annual application might increase yield in this system based on these data and results reported at other locations (Jeppsson, 2000; Strik et al., 2003). Furthermore, multiple annual fertilizer applications could be an interesting avenue to explore and are often recommended for other berries to provide adequate nutrient throughout the growing season (Hanson, 2006; Pavlis, 2006). For example, split annual applications of urea (at budbreak and at petal fall) resulted in 10\% higher yields in total (over 5 years) than the same amount in a single annual application (Hanson and Retamales, 1992). Splitting rates into annual applications could be particularly important for minimizing the potential runoff of fertilizers (Renou et al., 2000).

The fertilizer application methods used here had no effect on black chokeberry development, but incorporating the fertilizer slowed down weed invasion. Nevertheless, this species showed a very high tolerance to weeds because treatments with high weed competition (surface application, high doses) did not impede growth of black chokeberry. In cut-over sites, however, incorporation of the fertilizer into the soil would be of interest to peatland managers because weeds and herbicides runoff can be potential sources of contamination in peat harvested nearby.

During the second growing season, mulch treatment proved to be beneficial for the vegetative development of black chokeberry. Effect of plastic mulch on yield has not been measured yet, but it is likely that yield will also increased with mulch, as reported for other small fruit (e.g., blueberry; Karp et al., 2006) The black polyethylene plastic mulch is known to provide good weed control, which can in turn accelerate growth of plants by decreasing competition. However, given that black chokeberry is weed-tolerant, lower competition is probably not the main direct cause of the improved growth. The plastic mulch raised soil temperatures, which stimulated rapid plant growth (Lament, 1993). Increased soil temperature under the mulch could explain the differences observed in this study because peat has a low thermal conductivity and is slow to reheat in spring (Virkajärvi and Huhta, 1996). If the objective of the planting is achieving commercial fruit production, plastic mulch is probably the best method to promote vegetative development and potential yield, although the latter was not measured in this experiment, and to control weeds. Then, one has to consider the use of drip irrigation and fertigation. If black chokeberries were to be used for restoration projects, mulch would not be necessary. The incorporation of a fertilizer into the soil would be enough to suppress weeds invasion if this was considered a problem by the peatland manager.

\section{Conclusion}

These experiments revealed that fertilized black chokeberry seedlings are easy to establish in cut-over peatlands. This plant can be an excellent complement to standard practices for peatland restoration; it provides refuge and food for birds, and it can act as a windbreak and increase the aesthetics of a site. A low rate of fertilizer such as $131.2 \mathrm{~g} /$ plant $(1.7 \mathrm{~N}-4.1 \mathrm{P}-12 \mathrm{~K})$ is required to ensure the long-term survival and substantial growth of the plants.

Black chokeberry can be planted on cutover peatlands for small fruit production. According to our results, yield increases with increasing fertilizer rate. Annual fertilizer applications improved vegetative development, but future trials are needed to test which application frequency and cultivars would be best for fruit production. Mulch also increased short-term vegetative development of plants and could therefore improve initial establishment and fruit production.

\section{Literature Cited}

Andriesse, J.P. 1988. Nature and management of tropical peat soils. FAO Soils Bul. 59 .

Aro, L. and S. Kaunisto. 2003. Effect of refertilisation and growing density on the nutrition, growth and root development of young Scots pine stands in a peat cutaway area with deep peat layers. Suo 54:49-68 (abstr.).

Environment Canada. 2006a. Canada climate normals 1971-2000, Drummondville, Quebec. Environment Canada, Ottawa. 10 Jan. 2006. <http:// www.climate.weatheroffice.ec.gc.ca/climate_ normals/results_f.html>.

Environment Canada. 2006b. Monthly data report for 2000 to 2005, Drummondville, Québec. Environment Canada, Ottawa. 10 Jan. 2006. $<$ http://www.climate.weatheroffice.ec.gc.ca/ climateData/monthlydata_f.html $>$.

Finn, C. 1999. Temperate berry crops. Proc. Fourth Natl. Symp. New crops new uses: Biodiversity agricultural sustainability. p. 324-334.

Gasiorowski, K., K. Szyba, B. Brokos, B. Kolaczynska, M. Jankowiak-Wlodarczyk, and J. Oszmianski. 1997. Antimutagenic activity of anthocyanins isolated from Aronia melanocarpa fruits. Cancer Lett. 119:37-46.

Hamel, J.-M. 1986. Pépinière: Choix du sol et du substrat de culture, fertilisation. Conseil des productions végétales du Québec, Ministère de l'agriculture, des pêcheries et de l'alimentation, Gouvernement du Québec, Québec, Canada. AGDEX 270-500.

Hanson, E.J. 2006. Nitrogen fertilization of highbush blueberry, p. 347-351. In: Lopes da Fonseca, L. and F. Romero Muñoz (eds.). Proc VIIIth IS on Vaccinium Culture, Acta Hort. 715. ISHS.

Hanson, E.J. and J.B. Retamales. 1992. Effect of nitrogen source and timing on highbush blueberry performance. HortScience 27:12651267.

Jeppsson, N. 2000. The effects of fertilizer rate on vegetative growth, yield and fruit quality, with special respect to pigments, in black chokeberry (Aronia melanocarpa) cv. 'Viking'. Scientia Hort. 83:127-137.

Karp, K., M. Noormets, M. Starast, and T. Paal. 2006. The influence of mulching on nutrition and yield of 'Northblue' blueberry. p. 301-305. In: Lopes da Fonseca, L. and F. Romero Muñoz (eds.). Proc VIIIth IS on Vaccinium Culture, Acta Hort. 715. ISHS.

Kask, K. 1987. Large-fruited black chokeberry (Aronia Melanocarpa). Fruit Var. J. 41:47.

Kukkonen, S., M. Uosukainen, and M. Vestberg. 1999. Cultivation of strawberry on mined peat bogs. Proc. Intl. Peat Symp. 99 (abstr.).

Lament, W.J., Jr. 1993. Plastic mulches for the production of vegetable crops. HortTechnology 3:35-39.

Lynch-Stewart, P. 1992. No net loss: Implementing 'no net loss' goals to conserve wetlands in Canada. North American Wetlands Conservation Council, Ottawa, Canada.

McKay, S.A. 2001. Demand increasing for aronia and elderberry in North America. New York Fruit Qrtly. 9:2-3.

Myllis, M. 1996. Agriculture on peatlands, p. 64-71. In: Vasander, H. (ed.). Peatlands in Finland. Finnish Peatland Society, Helsinki, Finland.

Noormets, M. 2006. Some aspects of flower biology of lowbush blueberry (Vaccinium angustifolium Ait.) and vetlvet-leaf blueberry ( $V$. myrtilloides Michx.); cultural management of lowbush blueberry and cranberry (Oxycoccus palustris Pers.) on exhausted milled peat areas, Estonian Univ. Life Sci., Tartu, PhD Thesis.

Noormets, M., T. Köster, K. Karp, T. Paal, and T. Tõnutare. 2004. The recultivation of opencast peatland in Estonia. Proc. 12th Intl. Peat Congr. p. 1195-1201.

Paal, T. 1992. On cultivating European cranberry in Estonia. J. Small Fruit Viticult. 1:59-61. 
Paal, T. and J. Paal. 2002. Rehabilitaiton of milled peat areas by cranberry (Oxycoccus palustris L.) plantations. Proc. Intl. Peat Symp. p. 280-282.

Pavlis, G.C. 2006. Blueberry fruit quality and yields as affected by fertilization. p. 353-355 In: Lopes da Fonseca, L. and F. Romero Muñoz (eds.). Proc VIIIth IS on Vaccinium Culture, Acta Hort. 715. ISHS.

Poulin, M., L. Rochefort, F. Quinty, and C. Lavoie. 2005. Spontaneous revegetation of mined peatlands in eastern Canada. Can. J. Bot. 83:539-557.

Renou, F., S. Jones, and E.P. Farrell. 2000. Leaching of phosphorus fertilizer applied on cutaway peatland forests recently established in central Ireland. Proc. 11th Intl. Peat Congr. p. 984-990.
Richer, C., J.-A. Rioux, and J. Côté. 1997. Aronia melanocarpa (Michx.) Elliott, p. 32-36. In: Rusticité et croissance de plantes ligneuses ornementales au Québec. Tome II. Résultats et recommandations du REPLOQ. Conseil des productions végétales du Québec Inc., Québec, Canada.

Rochefort, L., F. Quinty, S. Campeau, K. Johnson, and T. Malterer. 2003. North American approach to the restoration of Sphagnum dominated peatlands. Wetlands Ecol. Manage. 11:3-20.

Rousseau, H. and D. Bergeron. 2003. Native plant development program. Acta Hort. 626:383-388.

Strik, B., C. Finn, and R. Wrolstad. 2003. Performance of chokeberry (Aronia melanocarpa) in Oregon, USA. Acta Hort. 626:439-441.
Vestberg, M., M. Uosukainen, S. Kukkonen, M. Räkköläinen, M. Rahtola, and P. Simojoki. 1999. Cultivation of horticultural crops on mined peat bogs. Proc. Intl. Peat Symp. 118 (abstr.).

Virkajärvi, P. and H. Huhta. 1996. Agricultural utilization of cut-away peatlands, p. 135137. In: Vasander, H. (ed.). Peatlands in Finland. Finnish Peatland Society, Helsinki, Finland.

Wind-Mulder, H.L., L. Rochefort, and D.H. Vitt. 1996. Water and peat chemistry comparisons of natural and post-harvested peatlands across Canada and their relevance to peatland restoration. Ecol. Eng. 7:161181 . 